\title{
Farmers Response towards the Traps for Controlling Gundhi Bug in Rice Field of Arunachal Pradesh: An Evaluation Study
}

\author{
Anup Chandra, Manish Kanwat*, Bhoben Pait and H. Kalita
}

ICAR Research Complex for NEH Region, Arunachal Pradesh Center, Basar-791101, West Siang District, Arunachal Pradesh, India

*Corresponding author

\begin{tabular}{|l|}
\hline Ke y w o r d s \\
$\begin{array}{l}\text { Farmers, Gundhi } \\
\text { Bug, Rice field, } \\
\text { Arunachal Pradesh }\end{array}$ \\
\hline Article Info \\
\hline $\begin{array}{l}\text { Accepted: } \\
\text { 04 August } 2018 \\
\text { Available Online: } \\
\text { 10 September } 2018\end{array}$ \\
\hline
\end{tabular}

\section{A B S T R A C T}

Rice is the world's most important food crop and a primary source of food for more than half of the world's population. More than $70 \%$ of the people of the Arunachal Pradesh are engaged in agriculture. Some traditional lures used in north east region of India like fermented fish, Puntius spp., fermented paste made up of the same, rotten pineapple, rotten crab, rotten frog and a dry fish, Harpadon nehereus were evaluated for the trapping potential against gundhi bug. Maximum numbers of bugs were trapped with rotten frog (11.7) followed by the fermented paste prepared from Puntius spp. (11.4). The next best lures found were fermented fish, Puntius spp. and dry fish, H. nehereus with 7.6 bugs per trap in a week, for both the lures. The trapping potential of rotten crab showed 4.4 bugs per trap in a week whereas the rotten pineapple with 0.7 bugs per trap in a week was observed as poor as control ( 0.3 bugs per trap in a week). Therefore, it can be interpreted from the study that the rotten frog and the fermented paste prepared from Puntius spp. had the maximum potential among the lures evaluated. Apart from this, more among the evaluated lures like fermented fish (Puntius spp.), dry fish (H. nehereus) and rotten crab can also be used for the purpose of mass trapping of gundhi bugs depending on their trapping potential and ease of availability.

\section{Introduction}

Rice is the world's most important food crop and a primary source of food for more than half of the world's population. More than 70\% of the people of the Arunachal Pradesh are engaged in agriculture. Among the various agricultural crops, rice is the most dominant crop occupying $80 \%$ of the total agricultural land of the region (Firake et al., 2013). The farmers from developed from different ethnic diversity of the region have developed their own system for management the crops from different pest and diseases with the help of using Indigenous traditional knowledge. The North eastern region of India is a treasure of natural products pertaining to agriculture, food, medicine and natural resource management. Particularly Arunachal Pradesh has over 100 tribes and communities, each having their unique traditional wisdom developed through the ages. ITKs are ecofriendly and compatible to other pest management practices (Singh et al., 2008). Some indigenous traps are very famous viz. fermented fish, Puntius spp., fermented paste 
made up of the same, rotten pineapple, rotten crab, rotten frog and a dry fish, Harpadon nehereus were evaluated for the trapping potential against Gundhi bug (Mazumder et al., 2013). As the traps are placed openly, bugs are attracted towards it but are not getting trapped and killed and instead of protecting the main crop, attracts of its population. Although, conceptually it is assumed that the bugs are diverted from the main crop but having additional food resources, their population goes on increasing, ultimately causing more damage to the crop which necessitate the use of traps.

\section{Materials and Methods}

Six leading rice-growing ethnic communities of Arunachal Pradesh were purposively selected and these are West Siang (Galo), East Siang (Adi), Upper Subansiri (Tagin), Lower Subansiri (Apatani)and Namsai (khamti)./m,. Twenty-five traditional rice farmers of various ages were randomly selected from each of the aforementioned district, totaling to 160 respondents. Personal interviews using interview schedule and focus group discussions were carried out to identify the trapping performance of different locally known indigenous traps, to evaluate the trap effectiveness and durability of the lure tested by ICAR A.P. Centre, Basarin against the control management practices of gundhi bug in the province. The content of the interview schedule was validated and tested by the seasoned researchers of the Indian Council of Agricultural Research Complex for NEH Region Arunachal Pradesh Centre, Basar Arunachal Pradesh and Krishi Vigyan Kendra, Anjaw. Descriptive statistics such as frequency, percentage, and mean statistics were used in the presentation of data. Traditionally used and locally available materials (lures) like fermented fish, Puntius spp. $\left(\mathrm{T}_{1}\right)$, fermented paste made up from it (T2) rotten pineapple $\left(\mathrm{T}_{3}\right)$, dead-rotten crab $\left(\mathrm{T}_{4}\right)$, dead-rotten frog $\left(\mathrm{T}_{5}\right)$ and a dry fish
Harpadon nehereus (Bombay duck) $\left(\mathrm{T}_{6}\right)$ were selected as treatments and replicated as per complete randomized design. The lures selected were placed inside the plastic jars hanging from the top cover through a thin metallic binding wire. Empty jars, without any lure, were installed as control $\left(\mathrm{T}_{7}\right)$. The jars containing the lures as well as control were then placed randomly in the wet rice cultivation field handing on bamboo sticks at a level of height as of panicles. Two entry holes were made in each jars including the control and the holes were fitted with wire mesh in such a way that bugs once entered cannot pass out. Perception of farmers was also reflected towards the effective and sustainable practices of trapping the insect and pest of rice crops. Data on number of bugs trapped in a week were recorded for four consecutive weeks which were then subjected to square root transformation followed by statistical analysis (ANOVA). Primary data used were collected through structured questionnaire, interview schedule backed with focused group discussion in some cases. Only seventy six filled and returned data collecting instruments were used for this study. Some of the data collected included personal and socioeconomic parameters of the respondents, past and present experience of newly designed traps by the ICAR AP Centre Basar in against of Gundhi bug. Data were analyzed by descriptive statistics- frequency and percentages, Mean score and relationship analysis.

\section{Results and Discussion}

After gone through the questionnaire filled up by the farmers it was revealed that about $90 \%$ were about the local indigenous traps for useful for controlling the insect pest infestation and these are known from the seniors. Small holding farmers have regularly been using Indigenous traps for controlling the pest, however many of farmers were rely on chemicals for suppression of the pest 
immediately. An attempt was also made to find out the respondents' perceptions towards sustainable agricultural indicators in control of Gundhi bug in rice fields (Table 1). The respondents' perception about the management of rice from Gundhi bug prioritized according to means and CVs. Because CV depicts the variation of perception, lower $\mathrm{CV}$, i.e. lower variation of respondents' perceptions, for same mean, placed on higher rank. Because of belonging more than one statement to each indicator, it was not possible to organize statements according to their rank order.

As data show, A high proportion of farmers were found to believe that infestation of Gundhi bug was very impressively controlled by the ICAR deliberated traps and tested their efficacy on the field with the varied baits viz., fermented paste made up from Puntius spp. and dead rotten frog. As per the mean score depicts, majority of the respondents were agreed that management practices should be cost effective, therefore it can be easily approachable to all the farming community. According to Rahman (2013) also found while, their awareness remains mostly confined within visible impacts, their perception of intangible impacts was weak.

The respondents were fairly aware of the adverse environmental impact of applying synthetic chemicals and the residual effects of chemicals on crop health and environmental status. As mean scores depicts, majority of the respondents were in agreement with the application of chemicals. The perceived chemicals has destroyed the environment and cause the hazardous effects on human health. Most of them were against the use of chemicals in against the control of Gundhi bug and did not believe the process would lead to long term viable production. Most of them were supported the idea of pesticides is the easiest way to combat against pests, despite the awareness that insecticides are the major environment pollutant and their over application makes insect resistant this result was also supported by Rolling and Pretty (1997). On the contrary, the majority of the $(67.1 \%)$ respondents perceived tillage operations is the best suitable way to avoid the pests population from the field because it remove the unwanted plants from the field which may become into the host plants for different pests. There were least perception towards necessity of diversification and rotation in the rice-based farming system. As mean scores and CVs show, most of the respondents were not well aware that successive cultivation of a single crop causes an increase in pests invasion, majority of the farmers couldn't apply the method on their farm because of having small land size and flooded fields. There were different perceptions towards necessity of diversification and rotation in the rice- based farming systems. As mean scores and CVs show, most of the respondents were well aware that successive cultivation of a single crop causes an increase in pests' invasion. Also, a number of the respondents who applied diversification and rotation in their farming activities strongly emphasized that these practices had increased their farm's yield. Some of the respondents did not diversify their farms.

Most of the respondents couldn't apply the method on their farms because of having small land size and flooded fields. Although 30.6 and 31.8 of the respondent were in agreement with decreasing of pest invasion and soil erosion by diversification and rotation, respectively; however, their perceptions was not very positive about such practices. Because soil erosion is an intangible problem, as Rahman showed, perception about intangible impacts are weak. In the case of pest control by diversification and rotation, as mentioned above, a group of respondents who had been benefited rotation in their farms were 
in agreement with the statement. Their second crop included vegetable, alfalfa, sorghum, rice, barley and rapeseed. The rapeseed growers were a large subgroup who encountered to rapeseed's pest invasion. They thought diversification and rotation were cause of increased pest invasion. They argued every crop has its pest then several crops will bring into farm several pests. It can be resulted that, failure to adopt an innovation (rapeseed) will affect the adoption of other innovations (rotation). Majority of the respondents perceived that legume crops can improve soil fertility. But most of them (59.9\%) didn't believe that with rice- legume rotation, pest's population may be controlled. Most of the respondents had negative perception about biological control of rice pests. This perception is associated with unsuccessful experience of plant protection office for substitution of stem borer insecticide by Trichogramma fly.

Most of farmers had no access to Trichogramma fly. A small number of the respondents $(25.9 \%)$ perceived that biological control is best way for control of pests' population under economic threshold. On the contrary, as means and CVs. Data in Table 2 show the categorization of farmers according the effectiveness of lures against the control of gundhi bug in the study area. More than half (79.37\%) of the farmers shown the faith on fermented paste made up form Puntius spp. followed by the dead rotten frog $(78.12 \%)$ to control the gundhi bug in rice field. The farmers were preferred puntinus spp. over rotten frog because easy availability of the fish into the near surroundings. The decomposed mixture is usually spread on the terraces of the farms and it acts as repellent to insect pests. Use of fermented fish Puntius spp. was also performed satisfactorily with the response of more than 65.66 per cent of respondents after majority of $61.25 \%$ of respondents of dead rotten crab common pest control traditional practice adopted by most $(92.3 \%)$ of the farmers supported by Thapa et al., (2004). The ash is sprinkled on crop leaves (mostly vegetables) to act as corrosive materials and helps in desiccating water from insect body. Another popular traditional practice in the study area was indigenous traps used by majority $(94.5 \%)$ of the farmers to control rodents on their farms. Other traditional practices identified with the farmers in the study area were fermented water from locust bean seeds $(73.8 \%)$ and raw blood of the cow $(13.4 \%)$ that act as repellent to birds. This is an indication that farmers in the study area made use of locally available natural resources that is economically viable and sustainable.

\section{Trapping potential and effective durability of lure}

The statistical analysis revealed that the treatments were significant at $1 \%$ (CD 1.63) and $5 \%$ (CD 1.18) level of significance with $28.7 \%$ coefficient of variation. Maximum mean numbers of bugs were observed in the first week of installation of traps with 11.7 (Table 3) in case of rotten frog followed by the fermented paste prepared from Puntius spp. (11.4), both of which were recorded statistically at par with each other (Chandra et al., 2017). The next best lures found were fermented fish, Puntius spp. (intact form) and dry fish, $H$. nehereus with 7.6 bugs per trap in the first week, for both the lures.

On the other hand, the number of bugs trapped was observed in the rice field but still utmost effective in the second (2.3 bugs per trap) and the third week (0.6 bugs per trap) with the rotten frog but showed statistically nonsignificant difference with any of the treatments and so were the observations in the fourth week. Overall, the mean number of bugs trapped in the second, third and fourth week was negligible. The smell of the lures was effective only up to the first of installation of the traps where after it was lost in the second and subsequent weeks. 


\section{Designing of the trap}

Generally, in a trap, insecticides are used along with the lures to kill the trapped insects, but wire meshed entry holes of the traps showed too effective catch to devoid the requirement of insecticides. The entry holes of the traps were fitted with thin wire mesh in such a way that the bugs once entered cannot pass out, thereby killed inside the trap.

The traditional practice of fixing a dead-rotten carb of frog openly on a bamboo stick can be slightly modified in to this particular type of trap. An alternate method, bucket trap can also be used. The lures are placed hanging from the cover of the bucket through a thin wire whereas the lower level is fitted with kerosene mixed water (Chandra et al., 2017). Longitudinal cuts are made on the side walls for entry of the bugs. Bucket trap would be more durable and voluminous for mass trapping.
Factor influencing adoption of effective lures and designed low cost traps by ICAR Scientist

The data in Table 4 shows the distribution of respondents by factor influencing adoption of improved traps designed by the team of scientist of ICAR AP Centre, Basar and tested at multi-locations successfully but still there is some hesitation which may affects the adoption of suited and effective lure along with low-cost effective traps designed by the ICAR for controlling Gundhi bug. There are many factors influencing adoption of improved farm practices. The data is classified into following groups: Characteristics of the innovation, characteristics of the adopters, cultural factors and characteristics of the change agents, government policy and environmental factors.

Table.1 Percent distribution of the respondents according to agreement with the statement of sustainable indicators $(n=160)$

\begin{tabular}{|l|l|l|l|l|l|l|l|l|}
\hline Indicators & SA & A & UD & DA & SDA & Mean & CV & Rank \\
\hline Negative effects of synthetic chemicals & 52.9 & 40.6 & 1.8 & 2.9 & 1.8 & 4.14 & .25 & 2 \\
\hline Reducing use of pesticides & 4.1 & 63.0 & 18.2 & 11.2 & 3.5 & 3.53 & .25 & 3 \\
\hline Crop diversification and rotation & 5.9 & 52.9 & 17.1 & 20.6 & 3.5 & 3.37 & .26 & 6 \\
\hline Cultural Practices for pests' control & 2.3 & 67.1 & 12.4 & 14.1 & 4.1 & 3.49 & .26 & 5 \\
\hline Availability of local traps & 11.8 & 44.1 & 21.3 & 19.4 & 3.5 & 3.41 & .30 & 7 \\
\hline Effective control by ICAR designed traps & 35.9 & 52.9 & 2.3 & 7.1 & 1.8 & 4.14 & .22 & 1 \\
\hline Cost effective & 2.4 & 17.6 & 3.5 & 67.1 & 9.4 & 3.64 & .26 & 4 \\
\hline
\end{tabular}

Table.2 Distribution of farmers according to the effectiveness of different lure against the Gundhi bug control (160)

\begin{tabular}{|l|l|l|}
\hline Treatment/ Practices & Frequency & Percentage \\
\hline Ti- fermented fish Puntius spp. & 105 & 65.66 \\
\hline T2- fermented paste made up from Puntius spp. & 127 & 79.37 \\
\hline T3- rotten pineapple & 89 & 55.62 \\
\hline T4- dead rotten crab & 98 & 61.25 \\
\hline T5- dead rotten frog & 125 & 78.12 \\
\hline T6- dry fish Harpdaon neherus (Bombay duck) & 100 & 62.50 \\
\hline T7- empty jar without nay lure & 67 & 41.87 \\
\hline
\end{tabular}

Source field survey-2015 \& 2016 
Table.3 Assessment the potentiality of different lures

\begin{tabular}{|l|}
\hline Treatment/ Practices \\
\hline Ti- fermented fish puntius spp. \\
\hline T2- fermented paste made up from puntius spp. \\
\hline T3- rotten pineapple \\
\hline T4- dead rotten crab \\
\hline T5- dead rotten frog \\
\hline T6- dry fish Harpdaon neherus (Bombay duck) \\
\hline T7- empty jar without nay lure \\
\hline
\end{tabular}

Bugs trapped per trap under different treatments in first week of installation

\begin{tabular}{|c|}
\hline 7.7 \\
\hline 11.4 \\
\hline 0.7 \\
\hline 4.4 \\
\hline 11.7 \\
\hline 7.7 \\
\hline 0.5 \\
\hline
\end{tabular}

Table.4 Distribution of respondents by factors influencing adoption of improved farm practices

\begin{tabular}{|l|l|l|l|l|}
\hline & $\begin{array}{l}\text { Factors affecting adoption of suited lure and } \\
\text { effective traps }\end{array}$ & Respondents & Frequency & Percentage \\
\hline A & Characteristics of Innovation & 160 & 160 & 100.00 \\
\hline i) & Cost effective & 160 & 160 & 100.00 \\
\hline ii) & Relative advantage & 160 & 150 & 93.75 \\
\hline iii) & Technical appropriateness & 160 & 160 & 100.00 \\
\hline iv) & Simplicity of application (i.e. complexity) & 160 & 160 & 100.00 \\
\hline v) & Effectiveness & & & \\
\hline B. & Characteristics of Adopters & 160 & 160 & 100.00 \\
\hline $\mathbf{1}$ & Technical Skill & 160 & 160 & 100.00 \\
\hline $\mathbf{2}$ & Attitude towards change & 160 & 160 & 100.00 \\
\hline $\mathbf{3}$ & Attitude towards taking risk & 160 & 160 & 100.00 \\
\hline $\mathbf{4}$ & Income level & 160 & 98 & 61.25 \\
\hline $\mathbf{5}$ & Farmers exposure & 160 & 113 & 70.62 \\
\hline $\mathbf{6}$ & Years of farming experience & 160 & 160 & 100.00 \\
\hline $\mathbf{7}$ & Educational level & 160 & 101 & 63.12 \\
\hline $\mathbf{8}$ & Labor availability & & & \\
\hline C. & Cultural Factors & 160 & 160 & 100.00 \\
\hline $\mathbf{1}$ & Belief & 160 & 160 & 100.00 \\
\hline $\mathbf{2}$ & Norms & 160 & 160 & 100.00 \\
\hline $\mathbf{3}$ & Taboos & & & \\
\hline D. & Characteristics of Change Agents/Extension Agents & 160 & 130 & 81.25 \\
\hline $\mathbf{1}$ & Communication ability & 160 & 160 & 100.00 \\
\hline $\mathbf{2}$ & Aptitude & 160 & 160 & 100.00 \\
\hline $\mathbf{3}$ & Credibility & 160 & 134 & 84.37 \\
\hline $\mathbf{4}$ & Confidence & 160 & 160 & 100.00 \\
\hline E & Govt./ ICAR support & 160 & 160 & 100.00 \\
\hline F & Environmental Factors (weather condition) & & \\
\hline & & & \\
\hline
\end{tabular}


Table.5 Relationship between factors influencing adoption of lure and trap designed and developed by ICAR Scientists for controlling the gundhi bug infestation in rice crop

\begin{tabular}{|l|l|l|}
\hline & Factors affecting adoption of suited lure and effective traps & Percentage \\
\hline A & Characteristics of Innovation & \\
\hline i) & Cost effective & $0.359^{*}$ \\
\hline ii) & Relative advantage & $0.247^{*}$ \\
\hline iii) & Technical appropriateness & $-0.399^{*}$ \\
\hline iv) & Simplicity of application (i.e. complexity) & $0.368^{*}$ \\
\hline v) & Effectiveness & 0.277 \\
\hline B. & Characteristics of Adopters & \\
\hline $\mathbf{1}$ & Technical Skill & 0.073 \\
\hline $\mathbf{2}$ & Attitude towards change & 0.134 \\
\hline $\mathbf{3}$ & Attitude towards taking risk & 0.123 \\
\hline $\mathbf{4}$ & Income level & 0.172 \\
\hline $\mathbf{5}$ & Farmers exposure & 0.115 \\
\hline $\mathbf{6}$ & Years of farming experience & 0.091 \\
\hline $\mathbf{7}$ & Educational level & 0.113 \\
\hline $\mathbf{8}$ & Labor availability & 0.119 \\
\hline C. & Cultural Factors & \\
\hline $\mathbf{1}$ & Belief & $-0.269^{*}$ \\
\hline $\mathbf{2}$ & Norms & $-0.316^{*}$ \\
\hline $\mathbf{3}$ & Taboos & -0.131 \\
\hline D. & Characteristics of Change Agents/Extension Agents & \\
\hline $\mathbf{1}$ & Communication ability & $0.254^{*}$ \\
\hline $\mathbf{2}$ & Aptitude & 0.59 \\
\hline $\mathbf{3}$ & Credibility & $0.469^{*}$ \\
\hline $\mathbf{4}$ & Confidence & $0 . .179$ \\
\hline $\mathbf{E}$ & Govt./ ICAR support & 0.082 \\
\hline $\mathbf{F}$ & Environmental Factors (weather condition) & 0.109 \\
\hline & & \\
\hline
\end{tabular}

\section{Characteristics of Innovation}

A hundred percent respondents have shown their favorable response towards the cost effective, relative advantage, simplicity and effectiveness of the of technology and majority of the farmers believed that the package of technology has been more useful and realistic at the ground level by using their own available resources.

\section{Characteristics of adopters}

Majority of the farmers hundred percent were realized that technical skill, attitude towards change, attitude towards taking risk and education level about the utility of refined, low cost and effective technologies and income level of the respondents were the important dynamics which affects the adoption among the respondents respectively. Whereas, farmers exposure and years of 
farming experience are also the least important factors for the adoption of new improved technologies.

\section{Cultural factors}

A hundred percent respondents were recognized that belief, Norms and taboos always play bigger role in adoption of any new technologies in practices.

\section{Characteristics of change agents}

A hundred percent of each identified competency and credibility as factors of change agents that influence adoption of innovation. About 84.37 percent identified confidence, while 81.25 percent identified communication ability of the extension agents as one of the factors.

\section{Relationship between factors influencing adoption of innovation and adoption rate}

The data in Table 5 show the relationship between factors influencing adoption of effective lures and innovated the low cost trap for controlling the Gundhi bug in rice field of NEH Region particularly in Arunachal Pradesh. The data revealed that credibility $(\mathrm{r}=0.469)$, cost $(\mathrm{r}=0.359)$, communication ability $(\mathrm{r}=0.254)$ and relative advantage $(\mathrm{r}=0.247)$ had positive and significant relationship towards the adoption of suitable lure and trap controlled the gundhi bug attack on rice fields respectively

According to Laith M. Rousan (2007) was also supported that credibility, land tenure and divisibility and communication ability and relative advantage had also positive and significant relationship with adoption of innovation. However, technical appropriateness $(\mathrm{r}=-0.399)$, belief $(\mathrm{r}=-0.269)$ and Norms ( $\mathrm{r}=-0.269)$ had a negative but significant relationship with adoption towards the evaluated and identified the effective lures $\left(\mathrm{T}_{2}\right)$ and designed trap by ICAR in against of gundhi bug control. Other factors with positive but insignificant relationship are confidence $(\mathrm{r}=0.179)$, Aptitude $(\mathrm{r}=059)$, attitude towards change $(\mathrm{r}=0.134)$, farmers exposure $(\mathrm{r}=0.115)$, income level $(\mathrm{r}=0.172)$, level of education $(\mathrm{r}=0.13)$, aptitude $(\mathrm{r}=059)$, technical skill $(\mathrm{r}=0.073)$, government policy $(\mathrm{r}=0.082)$ and year of farming experience $(\mathrm{r}=0.091)$. Only taboo $(\mathrm{r}=-0.131)$ has a negative but insignificant relationship with the adoption of identified lure and trap for controlling the gundhi bug infestation.

In spite of the widespread use of chemical pesticides in rice production, traditional farmers in Arunachal Pradesh continuously patronize the use of indigenous knowledge system in pest management. The continued utilization may be attributed to the effectiveness, affordability, communicability, ecological soundness and sustainability of these practices in controlling rice pests. Indigenous pest control practices are highly and extensively utilized in the province before and until now. These practices were acquired from their ancestors and passed down from generation to generation by word of mouth. Indigenous practices are thus excellent alternatives to the costly chemical pesticides in conjunction with other organic based pest management component like organic based pest management like pest reflector and traps etc., Product of animal origin needs to be taken into consideration for developing effective pest management. This paper leads to the conclusion that proper identification, validation and documentation of the different lures available at locally and also innovate the lowcost traps from the available resources at very nominal cost. This study revealed that fermented paste prepared from Puntius spp. with the percent of 79.37 followed by the rotten frog with the percentage of 74.37 respondents this result was also supported by 
Muzaddadi (2013). Other traditionally known lures like crab and dry fish, H. nehereus also proved effective to be used for the purpose. The lures should be used inside the newly designed trap instead of fixing openly on a bamboo stick and has to be replaced at weekly interval to get an effective management of Gundhi bugs. The adoption towards the suited lures and newly designed traps were very good because the lure \& traps are cost effective and least complex to control the Gundhi bug in rice field.

\section{Acknowledgment}

The authors are grateful to the farmerrespondents of the selected rice-growing communities in West Siang (Galo), East Siang (Adi), Upper Subansiri (Tagin), Lower Subansiri (Apatani) and Namsai (khamti) for sharing their precious time and valuable inputs during the data collection. Sincere gratitude is likewise extended to the Heads of the villages who helped organize and facilitate the conduct of group discussions. Full appreciation is further given to the Director, ICAR RC for NEH Region for their inputs in refining the contents of this article.

\section{References}

Chandra, Anup et al., (2017). Puntius spp. as a Potential Lure AgainstGundhi Bug in North East Region of India.

Firake D. M., Lytan, D., Thubru, D. P., Behere, G. T., Firake P. D. \& Azad Thakur, N. S. (2013). Traditional Pest Management Practices and Beliefs of
Different Ethnic Tribes of Meghalaya, North Eastern Himalaya. Indian Journal of Hill Farming 26(1): 58-61.

Mazumder D, Deka SN, Pujari D, Das PK (2013). Traditional knowledge addopted by the farmers for management of rice pests in north bank plain zone of Assam. Ind. J. Tradit. Knowledge 12: $725-729$.

Muzaddadi AU (2013). Naturally evolved fermented fish products of northeast India (Seedal and Shidal) $-\mathrm{A}$ comparative study. Ind J Nat Prod Res 4: $170-177$.

Rahman, S., 2003. Environmental impacts of modern agricultural technology diffusion in Bangladesh: an analysis of farmers' perceptions and their determinants. Journal of Environmental Management 68: 183-191.

Roling, N. and J.N. Pretty, 1997. Extension's role in sustainable agricultural development. In: Improving agricultural extension, a reference manual. B.E. Swanson; R., P. Bentz and A.J. Sufranko (Eds.), FAO, Rome, Italy.

Singh, R.K. Singh, A. Tag, H. and Adicommunity, Traditional skill among the Adi tribes of Arunachal Pradesh, Ind. J. Trad. Knowl., 7(1): 27-36, (2008).

Thapa N, Pal J and Tamang J, Microbial diversity in Ngari, Hentak and Tungtap, fermented fish products of North east India, World J Microbial Biotech, 2004, 20, 599-607.

\section{How to cite this article:}

Anup Chandra, Manish Kanwat, Bhoben Pait and Kalita, H. 2018. Farmers Response towards the Traps for Controlling Gundhi Bug in Rice Field of Arunachal Pradesh: An Evaluation Study. Int.J.Curr.Microbiol.App.Sci. 7(09): 176-184.

doi: https://doi.org/10.20546/ijcmas.2018.709.022 